\title{
Pandemia e escolarização indígena: o enfrentamento da evasão escolar indígena pós-pandemia com o apoio da educação mediada pelas tecnologias
}

\author{
Ana Cláudia Vieira Braga ${ }^{1}$ \\ Francisco Darci Feitosa ${ }^{2}$ \\ Jorge Manoel Adão ${ }^{3}$ \\ Larissa Costa Melo ${ }^{4}$
}

\section{RESUMO}

Este artigo tem por objetivo apresentar o conjunto de estratégias e mecanismos pedagógicos empregados para o auxílio e manutenção da rotina escolar no Colégio Estadual Indígena Tupinambá do Acuípe de Baixo no município de Ilhéus no Estado da Bahia. Tais estratégias visaram incentivar a permanência dos atores escolares em isolamento social, principal forma de prevenção do contágio e da propagação do vírus responsável pela pandemia que assolou o mundo no ano de 2020 e inviabilizou o Ensino Presencial nas instituições públicas e privadas do Brasil. De forma mais específica, este estudo busca identificar quais são os resultados esperados no atendimento escolar, mediado pelas tecnologias no esforço de evitar a evasão escolar indígena, e no auxílio à manutenção da rotina de estudos para a permanência dos alunos no processo de escolarização pós-pandemia.

Palavras-chave: Educação. Escolarização Indígena. Tecnologias Educacionais. Evasão Escolar. Pandemia.

\footnotetext{
${ }^{1}$ anaclaudiaunb2012@gmail.com - Universidade de Brasília - UnB

2 franciscodarcifeitosa@gmail.com - Universidade Estadual de Goiás - UEG

3 jorgeadao@yahoo.com.br - Universidade Estadual de Goiás - UEG

${ }^{4}$ larissa.melo@enova.educacao.ba.gov.br - Secretaria Estadual de Educação da Bahia
} 


\section{Pandemic and indigenous schooling: facing post pandemic indigenous school evasion with the support of education mediated by technologies}

\section{ABSTRACT}

This article aims to present the set of pedagogical strategies and mechanisms used to help and maintain the school routine at the Tupinambá Indigenous State College of Acuipe de Baixo in the municipality of Ilhéus in the State of Bahia. Such strategies aimed to encourage the permanence of school actors in social isolation, which is the main form of prevention of contagion and the spread of the virus responsible for the pandemic that devastated the world in 2020 and made classroom teaching in public and private institutions of the Brazil. More specifically, in this study, we seek to identify what are the expected results in school care, mediated by technologies, in an effort to prevent indigenous school dropout and in helping to maintain the study routine for students to remain in the post-pandemic schooling process.

Keywords: Education. Indigenous schooling. Educational Technologies. School dropout. Pandemic. 


\section{INTRODUÇÃO}

Este artigo tem por objetivo apresentar o conjunto de estratégias e mecanismos pedagógicos empregados para o auxílio e manutenção da rotina escolar no Colégio Estadual Indígena Tupinambá do Acuípe de Baixo (CEITAB) no município de Ilhéus no Estado da Bahia durante o isolamento social, principal forma de prevenção do contágio e da propagação do vírus responsável pela pandemia que assolou o mundo no ano de 2020 e inviabilizou o Ensino Presencial nas Instituições de Ensino (IE) públicas do Brasil.

De modo mais específico, este estudo busca identificar quais são os resultados esperados no atendimento escolar mediado pelas tecnologias no esforço de evitar a evasão escolar indígena e no auxílio à manutenção da rotina de estudos dos alunos da escola indígena. Da mesma forma, pretende-se descrever as estratégias utilizadas pelo CEITAB para a garantia da permanência dos alunos no processo de escolarização pós-pandemia.

A história conhecida sobre a tentativa fracassada de escravização, a catequização pelos jesuítas e a campanha de educabilidade dos indígenas brasileiros remetem a uma dinâmica da transfiguração étnica que foi visualizada por Darcy Ribeiro e que estuda como os povos surgem e são transformados por forças bióticas - doenças como a COVID-19, mudanças genéticas - e ecossociológicas - por exemplo, o afastamento de povos indígenas de seus territórios e a propagação da pecuária em terras indígenas. Para Ribeiro (1970), esse processo de transfiguração diferencia-se do processo de aculturação, porque espelha o resultado das trocas culturais estabelecidas entre os povos originais das Américas e os colonizadores europeus. Tais trocas foram dominadas pela imposição da cultura europeia e pelo desprezo visível aos costumes e à organização social dos povos originários.

Todo o arcabouço legal sobre a minoria étnica indígena foi, em síntese, desenvolvido com base no princípio básico e comum ao Estado de Direito não indígena, que inclui o conceito de igualdade entre todas as pessoas, estas, assim consideradas, como as que detêm os atributos do ser humano, da espécie humana, sem nenhum tipo de discriminação. Já os estudos relativos à etnicidade focam nos direitos à existência, à identidade e às medidas positivas que evitem a discriminação direta ou indireta e que não entendam o reconhecimento da identidade étnica como uma espécie de prêmio de consolação pelo passado áspero pelo qual passaram os nativos indígenas.

A atual população indígena brasileira, segundo o Censo Demográfico realizado pelo IBGE em 2010, é de 817.963 indígenas, dos quais 502.783 vivem na zona rural e 315.180 habitam as zonas urbanas brasileiras (IBGE, 2011), totalizando 0,4\% da população brasileira e 305 etnias. Nesse total, estão incluídos os povos que já estão integrados à sociedade dos não indígenas há séculos, enquanto outros, em menor número, são considerados recém-contatados. Pesquisas a respeito de indígenas em contextos urbanos como a de Nunes (2010) - intitulada Aldeias urbanas ou cidades indígenas? - demonstram que a maioria dos indígenas brasileiros está integrada às práticas próprias da vida urbana. A escolarização de alguns é híbrida - bilíngue e multicultural na escola da aldeia ou na escola pública da cidade; de outros, é totalmente não indígena nas escolas públicas da cidade. 
Essa complexidade a respeito da realidade de integração indígena envolve aspectos profundos de infraestrutura e pesquisa, como: saúde, educação, socialização, transfiguração étnica, aculturação, etnicidade e, considerando o advento da sociedade digital, o embate contra o paradigma cultural de que indígena para ter direitos de indígena não pode usufruir das benesses tecnológicas da cibercultura. Esse tema abarca as etnias, os povos, as aldeias, as famílias e os indivíduos em início de aproximação ou completamente integrados, que têm acesso à escolarização.

Uma inquietação relacionada ao alto índice de desistência dos estudos por parte de alunos indígenas de uma unidade do Ensino Médio do Instituto Federal de Roraima (IFRR) levou o professor de Educação Física Mateus Sena Lopes a desenvolver sua dissertação de mestrado com o tema Evasão e Fracasso Escolar de Alunos de Comunidades Indígenas do IFRR - Câmpus Amajari: Um Estudo de Caso. Em sua pesquisa, Lopes (2017) constatou que a democratização da escola pública não inclui uma visão integral a respeito do processo de democratização da permanência do aluno indígena na escolarização e muito menos um debate amplo sobre a inclusão dos alunos indígenas, considerando verdadeiramente as especificidades desses discentes na escolarização e na cultura digital.

Outros fatores influenciam a permanência dos alunos na escola enquanto instituição, principalmente, os indígenas, que representam uma minoria étnica pouco considerada e respeitada em seus direitos específicos. A valorização e o desenvolvimento dessas especificidades contribuiriam de maneira significa para uma participação mais sólida e uma permanência muito maior desses povos no âmbito educacional, desde o processo da escolarização na Educação Básica até a continuidade no Ensino Superior.

A escola para as comunidades indígenas é, a partir de uma visão não indígena, uma possibilidade de desenvolvimento da dimensão socioeconômica com o intuito de obter maior acesso e segurança nas interações sociais necessárias à integração dos indígenas na sociedade não indígena como um meio de promoção com maior garantia e propriedade da inserção com equidade e interação social, econômica e cultural em uma sociedade não indígena que apresenta, tão tardiamente, a possibilidade da atuação do indígena em contextos diversos por tanto tempo generalizados e repletos de paradigmas. Considerando que a cultura original de um grupo étnico não se perde ou funde, mas adquire uma nova função, a inclusão desses povos na sociedade digital tende a acentuar e dar visibilidade para a cultura deles, contribuindo cada vez mais na manutenção dos valores tradicionais dos povos originários.

\section{ESCOLARIZAÇÃO INDÍGENA}

As escolas indígenas estão distribuídas em todo território nacional. A distribuição dessas escolas oferece uma variedade de características que refletem toda a diversidade de etnias e culturas encontradas nos povos indígenas brasileiros. A escolarização indígena também passa por garantias legais que proporcionam uma estruturação específica e geram protetivas culturais bem delineadas. A escola indígena representa um lugar de intersecção de culturas, um espaço onde a junção específica da cultura indígena e da inserção no espaço social não indígena elaboram ações multiculturais. Tal cultura é produzida com parentes, com o estar junto, com 
proximidades, com aulas em locais de retomadas territoriais; reconstruindo e renascendo em si mesmo.

Como fundamentação teórico-reflexiva dessa ideia do renascer em si mesmo, retomamos aqui o conceito de autopoiese de Romesin e García (1997). O autor define autopoiese a partir de um referencial individual e biológico de autoconstrução e mutação de sistemas; no entanto, também aplica o conceito de autopoiese para sistemas sociais, considerando esses sistemas como de terceira ordem autopoiética, em especial, porque a sociedade é constituída de organismos que se relacionam, e cada ser social é singular, individualmente ou em grupo, e realiza a autopoiese. As comunidades indígenas passam por reconstruções culturais a partir de si mesmas e de seus indivíduos e sua escolarização é um exemplo de autopoiese social, segundo o referido autor:

[...] pelo simples fato de que são, enquanto sistemas sociais [...] a forma de relação entre os organismos que os compõem e que notamos na vida cotidiana no preciso instante em que os diferenciamos em sua singularidade como tais a usar a noção de "sistema social" (ROMESIN; GARCÍA, 1997, p. 19, grifo do autor).

A instituição escola, no contexto indígena, é um evento que faz funcionar a vontade, o impulso de realização das coisas, das ideias e desejos dos indivíduos e do grupo. Ao percebermos que a escola surge como um estranho no ninho na cultura da educação indígena, constata-se que houve um movimento de renascimento e reconstrução da escolarização. Não foram os indígenas que se adaptaram à escola, mas sim a escola que precisou de novas estruturas para fazer sentido na cultura indígena.

As questões existentes sobre educação são abarcadas por vieses pedagógicos e também políticos, econômicos e sociais. Essa parece uma afirmação repetitiva, já que Paulo Freire (1987) apresentou, em sua vasta obra, esses quesitos como imprescindíveis para se refletir sobre a educação escolar. Apesar disso, ao voltarmos nosso olhar para a escolarização indígena percebemos que os vetores sociais, culturais e econômicos devem incluir o parâmetro de particularidade das etnias e da condição da escola indígena no cenário da educação brasileira.

As características específicas do CEITAB incluem a localização, passam pelo quadro funcional e alcançam o currículo.

\subsection{0 locus}

O CEITAB localiza-se na rodovia Ilhéus - Una, na altura do Km 30 no Acuípe de Baixo na cidade de llhéus no Estado da Bahia, dentro da comunidade indígena Tupinambá de Acuípe de Baixo. A comunidade de Acuípe de Baixo fica na região sul do município de Ilhéus e se limita com o município de Una. O rio Acuípe, que também passa nas comunidades de Acuípe de Cima e Acuípe do Meio, encontra-se com o mar no manguezal.

A comunidade indígena do Acuípe de Baixo mantém-se economicamente por meio da coleta de recursos naturais, do turismo, da atividade pesqueira, da agricultura e da venda de artesanato. Segundo o Projeto Pedagógico do CEITAB (2017): 
O terreno no qual está construído o colégio é uma área de retomada indígena, no qual já vivenciou tensos momentos de reintegração da área. É uma área grande onde possui além do colégio um posto de saúde e os moradores que vivem na comunidade no entorno da escola. Quanto ao prédio foi uma construção da Prefeitura de llhéus que cedeu uma sala em 2001. Ao lado funcionava uma sala de aula que pertencia à prefeitura e do outro lado, uma sala que pertencia ao Colégio Tupinambá de Olivença. Em 2011 após a ocupação da área o prédio tornou-se apenas escola indígena pertencente à rede estadual de ensino. Além desta área da escola sede, funcionam também dois núcleos: o Núcleo do Acuípe do Meio e o Núcleo do Acuípe de Baixo II, em comunidades com o mesmo nome dos núcleos (CEITAB, 2017, p. 05).

Por ser a área indígena em que está localizado o CEITAB objeto de retomada, o prédio da atual escola, que foi uma construção da prefeitura de llhéus, teve cedida aos indígenas uma sala em 2001. Ao lado, funcionava uma sala de aula que pertencia à prefeitura e do outro lado, uma sala que pertencia ao Colégio Tupinambá de Olivença. Em 2011, após a ocupação, a área do prédio tornou-se apenas escola indígena pertencente à rede estadual de ensino. Além dessa área da escola sede, funcionam em outras aldeias também duas salas de aula: o Núcleo do Acuípe do Meio e o Núcleo do Acuípe de Baixo II.

A Secretaria de Educação da Bahia (SE-BA) organiza-se para atender às solicitações do Estado a partir do Decreto $\mathrm{n}^{\circ} 8.471 / 03$, que criou a categoria Escolas Indígenas no âmbito do Sistema Estadual de Ensino, e a Resolução n 106/04 (BRASIL, 2012), do Conselho Estadual de Educação, que estabelece diretrizes e procedimentos para a organização e a oferta da educação escolar indígena. Desse modo, também foram criadas e organizadas várias escolas e, ao final de 2003, foram instituídas 46 escolas como colégios indígenas, com o contrato de professores pelo Regime de Direito Administrativo (REDA) com duração de quatro anos (SANTANA, 2015).

\subsection{A evasão escolar indígena}

Em escolas específicas das aldeias ou nas localizadas em territórios indígenas, a evasão escolar acontece por vários fatores, entre eles: as dificuldades de acesso às áreas das Unidades Escolares (UE), tendo em vista que esses estudantes residem em zonas rurais remotas e são totalmente dependentes de transporte escolar que, por sua vez, costuma apresentar desgastes constantes, advindos dos percursos e volume diário de trechos, ainda que a manutenção dos veículos venha a ocorrer constantemente; outro aspecto relevante é a necessidade que os estudantes têm de desenvolver atividades laborais informais para garantir o sustento da família.

A falta de crédito no papel da escola na educação indígena é percebida com frequência e, em muitos episódios, ainda que manifestado no aluno o desejo de profissionalizar-se e retornar ao seu espaço de origem, os alunos das escolas indígenas não demonstram confiança no paradigma de que a educação escolar indígena possa ser a ponte que leve à ocupação de outros espaços sociais.

Considerando que os fatores de risco e os dados sobre evasão escolar indígena em situação de normalidade nas atividades escolares presenciais já são preocupantes, a gestão do CEITAB reuniu sua equipe de professores e por meio de debates com o seu corpo docente, traçou 
estratégias que auxiliassem, não só a orientação pedagógica dos estudantes, mantendo a rotina e o estímulo aos estudos e assim garantindo o vínculo escolar, mas também, o incentivo da permanência das famílias em isolamento social, principal forma de prevenção para o contágio e propagação do vírus, indicada pela OMS e adotada pelas autoridades competentes do Estado da Bahia.

A realização desse projeto surgiu totalmente desvinculada de qualquer obrigação imposta pela Secretaria de Educação da Bahia, que, até o momento, não acenou com nenhuma informação institucional que sinalizasse para o aproveitamento dessas iniciativas de Ensino Remoto do CEITAB como horas letivas. Por esse fato mesmo é que o projeto carece de divulgação ampla no sentido de valorizar o esforço da gestão da escola em conjunto com a equipe docente e a comunidade pelo mérito nas ações em evitar a evasão escolar pós-pandemia.

Outro aspecto importante é o uso da educação mediada pelas Tecnologias Digitais de Educação, Comunicação e Expressão (TICE) que demonstra a superação de questões prementes à inclusão digital indígena, tanto dos docentes como dos discentes. O termo Tecnologias de Informação Comunicação e Expressão (daqui em diante TICE), que segundo Bellucci e Santos (2021):

\begin{abstract}
O conceito foi articulado a partir daquele de TIC (Tecnologias de Informação e Comunicação) e integra o termo "digital", para claramente excluir as tecnologias analógicas com esta mesma finalidade (informar e comunicar), bem como o termo "expressão", para claramente incluir as possibilidades inéditas de autoria de conteúdos diversos (textos, sons e imagens), proporcionadas pelas tecnologias decorrentes da Informática. As TICE fazem, portanto, alusão direta às possibilidades inéditas de se informar, de se comunicar e, sobretudo, de se expressar, que somente os aparatos digitais (como os computadores, os tablets e os telefones inteligentes), os ambientes virtuais (como as redes sociais, as páginas eletrônicas, os blogs e a própria Internet) permitem (BELLUCCI; SANTOS, 2021, p. 02).
\end{abstract}

Pierre Lévy afirma que pelo próprio fato de existir, uma estrutura social qualquer contribui para manter uma ordem, certa redundância no meio em que ela existe (LÉVY, 1993). Nesse aspecto, a questão da educação escolar indígena passa pela redundância da presença dos desafios já existentes na educação escolar em geral, com o adendo de que a escolarização indígena tem especificidades delicadas, já que a escola, na realidade da cultura indígena, constitui-se da representação institucional da cultura não indígena dominante.

\title{
2.3 O projeto educacional mediado pelas tecnologias educacionais
}

A cultura digital surge como mais uma vertente da cultura não indígena que entra na escolarização dos povos tradicionais e, por isso, já está presente na vida escolar dos alunos e professores indígenas. Nem bem está claro o papel social da escola na cultura indígena e já se delineiam outras questões sobre a inclusão digital na educação nas aldeias. A cultura digital, no entanto, contribui para pôr em prática o protagonismo e as reivindicações dos povos indígenas de maneira mais extensa e na escola, se trabalhada com foco na inclusão digital ampla e democrática. 
Para avançar no cumprimento dos planejamentos do atendimento de educação remota proposto pela equipe educacional do CEITAB, foi necessário fazer um mapeamento detalhado de quais estudantes da aldeia, por turma, teriam condições tecnológicas para fazer parte do grupo de WhatsApp da sua turma. Para isso, os líderes de classe foram convidados a buscar, inserir e administrar os grupos de estudantes de cada turma liderada e, assim, funcionar como um elo entre o corpo docente e discente.

No projeto, há o emprego de metodologias ativas baseadas no mobile learning, ou mais conhecida e empregada no Brasil como aprendizagem nômade, em que há o uso de dispositivos móveis e aplicativos, e seu uso procurou considerar o entendimento de que as pedagogias indígenas devem ser pautadas em consonância com os interesses da comunidade.

Outro ponto presente no uso da aprendizagem nômade reflete a questão de que a escola não é o único lugar de aprendizagem, o que nos envia ao posicionamento de que os povos indígenas desejam manter vivas as suas formas de educação tradicional, que podem contribuir na formação de uma política e uma prática educacional adequadas, capazes de atender aos anseios, interesses e necessidades diárias da realidade atual.

Por último, a escola é, nas comunidades indígenas, um espaço de ratificação do contato com não indígenas, e isso faz das instituições educacionais presentes nas aldeias um espaço dinâmico de práticas ancestrais mescladas com as práticas sociais dos não indígenas, os quais são os detentores da organização das escolas e do uso das tecnologias.

A Educação Infantil do CEITAB formou um grupo virtual com todos os pais, mães ou responsáveis e vem desenvolvendo atividades diárias no turno de suas aulas regulares, mediado pelas professoras das turmas. O Ensino Fundamental I, bem como o tempo formativo I da EJA, partindo do diagnóstico realizado pelos professores nas primeiras semanas de aula, elaboraram um conjunto de atividades destinado a cada ano, com conteúdos específicos de língua portuguesa e matemática, inicialmente, desenvolvido em material impresso, aplicando a metodologia da sala de aula invertida do Ensino Híbrido. Para Bacich, Tanzi Neto e Trevizani (2015):

No ensino híbrido, na metodologia de sala de aula invertida, o estudante tem
contato com as informações antes de entrar em sala de aula o que possibilita a
concentração nas formas mais elevadas do trabalho cognitivo, ou seja,
aplicação, análise, síntese, significação e avaliação desse conhecimento que o
aluno construiu ocorrem em sala de aula na qual ele tem o apoio de seus pares
e do professor, o fato do estudante ter contato com o material instrucional
antes de adentrar à sala de aula apresenta diversos pontos positivos (BACICH;
TANZI NETO; TREVIZANI, 2015, p. 10).

Nesse sentido, o Ensino Híbrido integra as TICE como mediadoras das possibilidades de ensino trazendo novas formas de aprender e ensinar. Na distribuição do material impresso, os professores foram munidos dos Equipamentos de Proteção Individual (EPI) necessários e mobilizaram-se a entregar pessoalmente na casa de cada estudante, com os conteúdos selecionados por área, passando às famílias as orientações de acompanhamento e registro. As próximas atividades para este segmento acontecerão em sala de aula virtual para a maioria dos alunos que já disponibilizaram seus contatos e poderão acompanhar as propostas realizadas; os que sinalizaram não possuir acesso à internet, continuarão recebendo material em domicílio, já 
que o principal objetivo dessa proposta é que todos os alunos matriculados, tenham a oportunidade de estar inseridos nesse movimento.

As $1^{\mathrm{a}}$ e $2^{\mathrm{a}}$ séries do Ensino Médio foram contempladas com um horário especial semanal em que, durante um período de duas horas no turno da manhã, acontecem aulas virtuais com dois professores a cada dia. Por sugestão do próprio grupo de professores, a fim de proporcionar o acompanhamento dos responsáveis dos alunos do Ensino Médio, foi adicionado o contato telefônico atualizado de todos os familiares à secretaria da escola e à direção, e, diariamente, são repassadas informações referentes aos filhos via WhatsApp.

A $3^{\mathrm{a}}$ série do Ensino Médio sofreu várias reestruturações ao longo do período, pois foi a primeira turma a iniciar os trabalhos virtuais ainda no mês de março. A ideia inicial foi trabalhar com revisões e dificuldades dos alunos em pontos chaves das disciplinas. Após a primeira avaliação docente, foi verificado um aproveitamento dessas atividades por menos de $50 \%$ dos estudantes. Depois de um diálogo individual com os discentes, reformulou-se a sequência de atividades para dois professores por dia em turno oposto e com um tempo maior para a realização e envio das atividades; muitos usam dados móveis e a área não favorece a qualidade da internet.

Nesse desenvolvimento, a interação com os professores foi ampliada, porém, com o advento do Exame Nacional do Ensino Médio (ENEM), houve a necessidade de uma nova reelaboração e a partir de então, as disciplinas seriam contempladas nas áreas de conhecimento. Com foco na resolução de questões direcionadas a esse exame, agregou-se a essa nova roupagem um dia da semana para orientação profissional e o último dia da sequência para um simulado interdisciplinar, constituído de oito questões e uma redação, estabelecido o tempo de duas horas para acessar o grupo, verificar as questões, responder e finalizar. Após correção, os resultados serão enviados em porcentagem de acerto e a evolução também será pauta para análise pedagógica.

O tempo formativo II e III da Educação de Jovens e Adultos (EJA) também foi contemplado e passou a integrar dois grupos com objetivos distintos. O primeiro, contando com três professoras, integraria a disciplina à prática profissional; o segundo, com um grupo também de três docentes, pós-campanha de acesso às avaliações do ENEM e mais de 80\% com inscrição viabilizada pela própria escola, terá também um foco em conteúdos disciplinares voltados para esta prova.

O Ensino Fundamental I, último segmento a ser contemplado por ter, em sua maioria, acesso a recursos digitais por aparelhos dos pais, em momentos esporádicos, contou com a seguinte distribuição: $6^{\circ}$ e $7^{\circ}$ ano, atividades lúdicas voltadas para as disciplinas de português e matemática básica; $8^{\circ}$ ano, inserido no programa de monitoria e estudos, promovidos pela SEC/BA e executado por estudantes da própria UE que, com média acima de 8,0 nessas disciplinas, são selecionados e remunerados para auxiliar os colegas com dificuldades de desenvolvimento nas mesmas disciplinas. Neste momento de pandemia, essas orientações ocorrerão no ambiente do Classroom do Google; o $9^{\circ}$ ano segue a mesma dinâmica das séries iniciais do Ensino Médio.

Toda essa promoção de ensino por meio de atividades domiciliares e recursos digitais tem sido elaborada e planejada respeitando todas as exigências que um plano de aula coerente e 
coeso requer, desde os objetivos até a avaliação por intermédio de relatos, registros fotográficos e orais, contribuindo para que os feedbacks recebidos sirvam como um termômetro capaz de mensurar os resultados, avanços ou necessidade de reestruturação. Todo o material produzido tanto pelos professores quanto pelos alunos, neste momento de Ensino remoto, tem sido arquivado no Colégio para consulta da própria SEC/BA, do corpo da comunidade escolar e de quem, por meio de solicitação, interessar-se, colaborando, assim, de forma significativa para a melhoria da promoção e qualidade da educação escolar indígena de todo o território.

\section{CONSIDERAÇÕES FINAIS}

Além do objetivo principal desta ação promovida coletivamente pelo CEITAB, versar sobre alternativas de combate à evasão escolar por meio de rotinas pedagógicas, avaliar os resultados, sala por sala e por professor participante - cerca de $80 \%$ do quadro -, foi o ponto chave, pois trouxe consigo a perspectiva de também ressignificar a atividade docente, promovendo a tomada de consciência sobre a necessidade de adequação constante das estratégias e metodologias de ensino a partir dos objetivos anteriormente estabelecidos e da observação dos resultados notados ao longo do percurso das aprendizagens, seja em uma educação remota ou presencial.

O incentivo à participação em lives e atualizações gratuitas promovidas não somente pela $\mathrm{SEC} / \mathrm{BA}$, mas em todo o território nacional por nomes consagrados na educação, tem sido compartilhado constantemente no grupo pedagógico, para que também os docentes agreguem novos conhecimentos à sua prática pedagógica. As reuniões docentes têm acontecido, com a mediação da gestão, de maneira virtual, aproveitando os e-mails institucionais da Secretaria de Educação do Estado (ENOVA) e o aplicativo Meet, já facilitado pelo acesso ao correio eletrônico. Essas reuniões de avaliação e reelaboração das atividades têm ocorrido com base na publicação quinzenal de ampliação do decreto estadual e nos planos/sequências didáticas que também seguem essa quantificação quinzenal.

Pode-se, mesmo que parcialmente, mediante reuniões virtuais com o corpo docente de cada segmento, via aplicativo Meet, notar algumas inquietações dos professores quanto ao acompanhamento dos responsáveis pelos alunos nas aulas e atividades remotas, principalmente com relação aos grupos de alunos dos anos finais. Mas acredita-se que a mediação familiar e a construção do aluno autônomo e protagonista, ator educacional que recentemente surgiu pela contingência da pandemia, fazem parte de um processo educacional em andamento e, por isso, merecem um pouco mais de tempo para se consolidarem na escolarização indígena.

Com o advento da pandemia e a necessidade de que esse atendimento virtual se tornasse uma realidade, problemas como os de aproximação família-escola ficaram ainda mais evidentes e, apesar de em sua maioria, os próprios estudantes ou seus responsáveis acessaram algum recurso tecnológico e internet - a falta de experiência na utilização dessas ferramentas digitais para fins educacionais é real. Diante desse fato, em diversos momentos, foi importante o diálogo da própria direção da escola via WhatsApp diretamente com o responsável pelo aluno para avaliar possíveis dificuldades e melhoramentos no retorno à proposta ofertada. Em muitos casos, essa intermediação surtiu resultados positivos, como foi o caso da Educação Infantil que atingiu $100 \%$ de participação na realização da atividade diagnóstica, realizada ao final da terceira 
sequência de atividades, com a finalidade de construir um parecer descritivo individual dos alunos dessas turmas e, assim, poder elaborar novos planejamentos, com direcionamento específico.

Nas turmas de finalização da Educação Básica, a $3^{\circ}$ série do Ensino Médio e tempo formativo III - eixo VII da Educação de Jovens e adultos -, a resposta quanto à valorização dos materiais disponibilizados virtualmente pelos professores neste período, veio também, pela confirmação de inscrição de mais de $80 \%$ dos alunos dessas classes no Exame Nacional do Ensino Médio, o ENEM. A preocupação em preparar-se para a realização dessa avaliação, que alcança todo o território nacional, serviu também como incentivo para os docentes que têm se debruçado sobre novas formas de ensinar com base em metodologias ativas, bem como da utilização e domínio dos recursos digitais e dos meios tecnológicos.

Refletindo sobre a possibilidade desse contínuo situacional pandêmico se disseminar em outros momentos, nessa sociedade cada vez mais tecnológica, científica, imediatista e, muitas vezes, com deficiências socioemocionais claras, é que se percebe ainda mais urgente o trabalho mediado pelas tecnologias e o protagonismo dos discentes quanto aos estudos por vias digitais, mesmo em comunidades ainda tão remotas quanto é a realidade das comunidades indígenas, ainda que situadas em áreas urbanizadas, como é o caso do Colégio Estadual Indígena Tupinambá de Acuípe de Baixo.

Em se tratando principalmente do universo das escolas, no qual os aspectos cognitivos são fundamentais para o desenvolvimento profissional e social, as demandas são enormes e a situação atípica para todos os países deste planeta. Apesar disso, mesmo diante de tantas inquietações e angústias por grande parte da comunidade escolar, é possível experimentar a sensação do novo e a necessidade de promover um "renovo" constante, voltado para uma sociedade que se movimenta com a agilidade e a velocidade do advento tecnológico, capaz de construir pontes e criar redes conectadas de pessoas com interesses comuns, situação benéfica e estimulante para o exercício do compreender-se como parte integrante e igualmente responsável pela manutenção do mundo.

A partir do acolhimento dos resultados dessas ações educativas, são inevitáveis as reflexões acerca do papel da escola para os povos indígenas, e do entendimento sobre o que é a sala de aula e consequentemente onde se pode promover educação. Os espaços são inúmeros, o conhecimento e o autoconhecimento atrelados às relações interpessoais não se limitam a um espaço físico, ao contrário disso, ajudam a construir identidade e são capazes de consolidar o ser como social, cultural e emocional, capazes de promover bem-estar e desenvolvimento humanizado para consigo e para com o outro, mesmo em isolamento social e restrição do contato físico.

Pensar a educação digital como aliada para a integração, a partilha, a aprendizagem e consequentemente a construção de novos conhecimentos e de novas formas de comportamento social por meio da mediação educacional, é algo, por certo, intrigante e inovador, mas acima de tudo necessário em um panorama de distanciamento e, sem dúvida, de sequelas inimagináveis nos mais diferentes contextos. 


\section{REFERÊNCIAS}

BACICH, L.; TANZI NETO, A.; TREVIZANI, F. M. Ensino Híbrido: Personalização e Tecnologia na Educação. Porto Alegre: PENSO, 2015.

BELLUCCI, J. N.; SANTOS, G. L. TICE orientadas a indivíduos com TA: uma revisão narrativa e seus apontamentos. Linhas Críticas, Brasília, DF, v. 27, p. 1-20, jan./dez. 2021. Disponível em: https://periodicos.unb.br/index.php/linhascriticas/article/view/36040. Acesso em: 26 fev. 2021.

BRASIL. Ministério da Educação. Conselho Nacional de Educação. Resolução n 5, de 22 de junho de 2012. Define Diretrizes Curriculares Nacionais para a Educação Escolar Indígena na Educação Básica. Brasília: MEC, 2012. Disponível em:

http://portal.mec.gov.br/index.php?option=com_docman\&view=download\&alias=11074-rceb005-12pdf\&category_slug=junho-2012-pdf\&Itemid=30192. Acesso em: 26 fev. 2021.

COLÉGIO ESTADUAL INDÍGENA TUPINAMBÁ DE ACUÍPE DE BAIXO (CEITAB). Projeto Político Pedagógico. Ilhéus: CEITAB, 2017.

FREIRE, P. Pedagogia do Oprimido. Rio de Janeiro: Paz e Terra, 1987.

INSTITUTO BRASILEIRO DE GEOGRAFIA E ESTATÍSTICA (IBGE). Censo Demográfico 2010: características da população e dos domicílios: resultados do universo. Rio de Janeiro: IBGE, 2011. Disponível em: https://biblioteca.ibge.gov.br/visualizacao/periodicos/93/cd_2010_caracteristicas_populacao_domicilios .pdf. Acesso em: 26 fev. 2021.

LÉVY, P. Cibercultura. São Paulo: Editora 34, 1993.

LOPES, M. S. Evasão e Fracasso Escolar de Alunos de Comunidades Indígenas do Instituto Federal de Roraima/Campus Amajari: um estudo de caso. 2017. Dissertação (Mestrado em Educação)- Programa de Pós Graduação em Educação, Universidade Federal de Juiz de Fora, Juiz de Fora, 2017. Disponível em: https://repositorio.ufjf.br/jspui/handle/ufjf/5792. Acesso em: 26 fev. 2021.

ROMESIN, H. M.; GARCÍA, F. J. V. De máquinas e seres vivos: autopoiese: a organização do vivo. 3. ed. Porto Alegre: Artmed, 1997.

NUNES, E. S. Aldeias Urbanas ou Cidades Indígenas? Reflexões sobre índios e cidades. Espaço Ameríndio, Porto Alegre, v. 4, n. 1, p. 9-30, jan./jun. 2010. Disponível em:

https://seer.ufrgs.br/EspacoAmerindio/article/view/8289/7642. Acesso em: 26 fev. 2021.

RIBEIRO, D. As Américas e a civilização: processo de formação e causas do desenvolvimento desigual dos povos americanos. Rio de Janeiro: Civilização, 1970.

SANTANA, J. V. J. A letra é a mesma, mas a cultura é diferente: a escola dos Tupinambá de Olivença. 2015. Tese (Doutorado em Antropologia Social)- Programa de Pós-Graduação em Antropologia Social, Universidade Federal de São Carlos, São Carlos, 2015. Disponível em:

https://repositorio.ufscar.br/handle/ufscar/7680. Acesso em: 26 fev. 2021. 